\title{
El archivo documental del Museo de San Isidro de Madrid The documental archive of San Isidro Museum
}

\author{
Salvador Quero Castro \\ Museo de San Isidro. Madrid. salvadorqueroc@gmail.es
}

Recibido 30/05/2015

Aceptado 22/09/2015

\section{Resumen}

En el Museo de San Isidro de Madrid hay un archivo documental de unos 100.000 documentos de diferentes procedencias. El más voluminoso (unos 80.000 documentos) corresponde al archivo personal de Julio Martínez SantaOlalla con márgenes cronológicos entre 1922 y 1968. El archivo de José Pérez de Barradas cubre entre 1917 y 1955 aproximadamente y se refiere a la arqueología madrileña entre 1920 y 1942 y a la antropología americana de los años 40 y 50 . Otros fondos son los propios de la actividad científica y administrativa del Museo Prehistórico Municipal, Instituto Arqueológico y Museo de San Isidro. Este archivo en proceso de catalogación es clave para el conocimiento de la historiografía de la arqueología española.

Palabras clave: Museo de San Isidro, Julio Martínez Santa-Olalla, José Pérez de Barradas.

\begin{abstract}
In the San Isidro Museum in Madrid, there is an investigation archive of around 100.000 documents proceeding from several sources. The largest of these (around 80.000 documents), is Julio Martinez Santaolalla's personal archive, which covers the period between 1922 and 1968. The archive belonging to José Pérez de Barradas provides documentation about Madrid's archeology between the 1917 and 1955 as well as some American anthropology during the $40 \mathrm{~s}$ and the $50 \mathrm{~s}$. At the same time, there are other files which illustrate the scientific and administrative activity that took place in Madrid's prehistorical and archaeological institutions. This archive is still being catalogued and will provide basic information about the functioning of Spanish Archaeological Historiography.
\end{abstract}

Key words: Saint Isidro Museum, Julio Martínez Santa-Olalla, José Pérez de Barradas.

\section{INTRODUCCIÓN}

El Museo de San Isidro de Madrid es la institución municipal heredera del Museo Prehistórico Municipal, organismo de investigación arqueológica que permaneció activo entre 1930 y la Guerra Civil, fundado y dirigido por José Pérez de Barradas. En 1942 se convirtió en Sección Arqueológica del Museo Municipal y el director se vio forzado a dimitir ante un expediente que se le incoó por ausencia del puesto de trabajo. Los fondos museográficos y los documentales pasaron a engrosar los del Museo Municipal y se convirtieron en un fondo cerrado.

En la posguerra Julio Martínez Santa-Olalla se hizo cargo del Seminario de Historia Primitiva del Hombre de la Universidad Central que había fundado Hugo Obermaier quien no se reincorporó a su cátedra tras la Guerra Civil. Esta institución fue prácticamente la única que realizó trabajos de arqueología en el Madrid de la posguerra, si bien quedaron inéditos. Los fondos 
museográficos y documentales de esta institución pasaron a engrosar las colecciones privadas de SantaOlalla.

En los primeros años 50 Julio Martínez SantaOlalla trató de fundar una institución inspirada en los institutos arqueológicos alemanes, para ello se apoyó en las buenas relaciones que mantenía con el Ministro de la Vivienda don José Luis Arrese, que era coleccionista y muy aficionado a la Arqueología, y con el Conde de Mayalde, amigo personal y también aficionado a la Arqueología, que fue un personaje clave desde su puesto en la Alcaldía de Madrid para la creación del Instituto Arqueológico Municipal por Acuerdo Plenario del Ayuntamiento de 21 de octubre de 1953 (Quero Castro, 1996) (Figura 1).

Con la creación del Instituto, por primera vez en nuestro país se planteó la recuperación del patrimonio arqueológico en su ciclo completo, desde la intervención en la ordenación del territorio para la prevención de la destrucción de posibles restos, hasta la exposición y publicación científica de los mismos.

La pérdida de influencia política de Julio Martínez Santa-Olalla hizo que tuviera que abandonar durante varios años la cátedra de Madrid y que se trasladara sucesivamente a las universidades de Zaragoza y Valencia. El Seminario de Historia Primitiva vinculado a la cátedra de la universidad madrileña fue desmantelado y sus colecciones, una mezcla de colecciones privadas de Santa-Olalla y de colecciones del Seminario, pasaron a depositarse en la sede del Instituto Arqueológico Municipal en su palacete del Parque de la Fuente del Berro de Madrid.

Coincidiendo con el declive político, la brillante actividad de los primeros años del Instituto Arqueológico quedó inédita y fue languideciendo al mismo tiempo que el personal femenino contraía matrimonio y tenía que abandonar (por imperativo legal) sus puestos de trabajo. La falta de apoyo institucional y de medios llegó al extremo de que cuando murió Julio Martínez Santa-Olalla en 1971 la plantilla se limitaba a la plaza del Director Vitalicio, Jefe de Trabajos de Campo y Laboratorios, un restaurador, dos obreros, un ordenanza y dos personas sin contrato entre las que se encontraba quien escribe estas líneas.

A su muerte el Ayuntamiento encarga la gestión del Instituto a la Dirección del Museo Municipal de la que

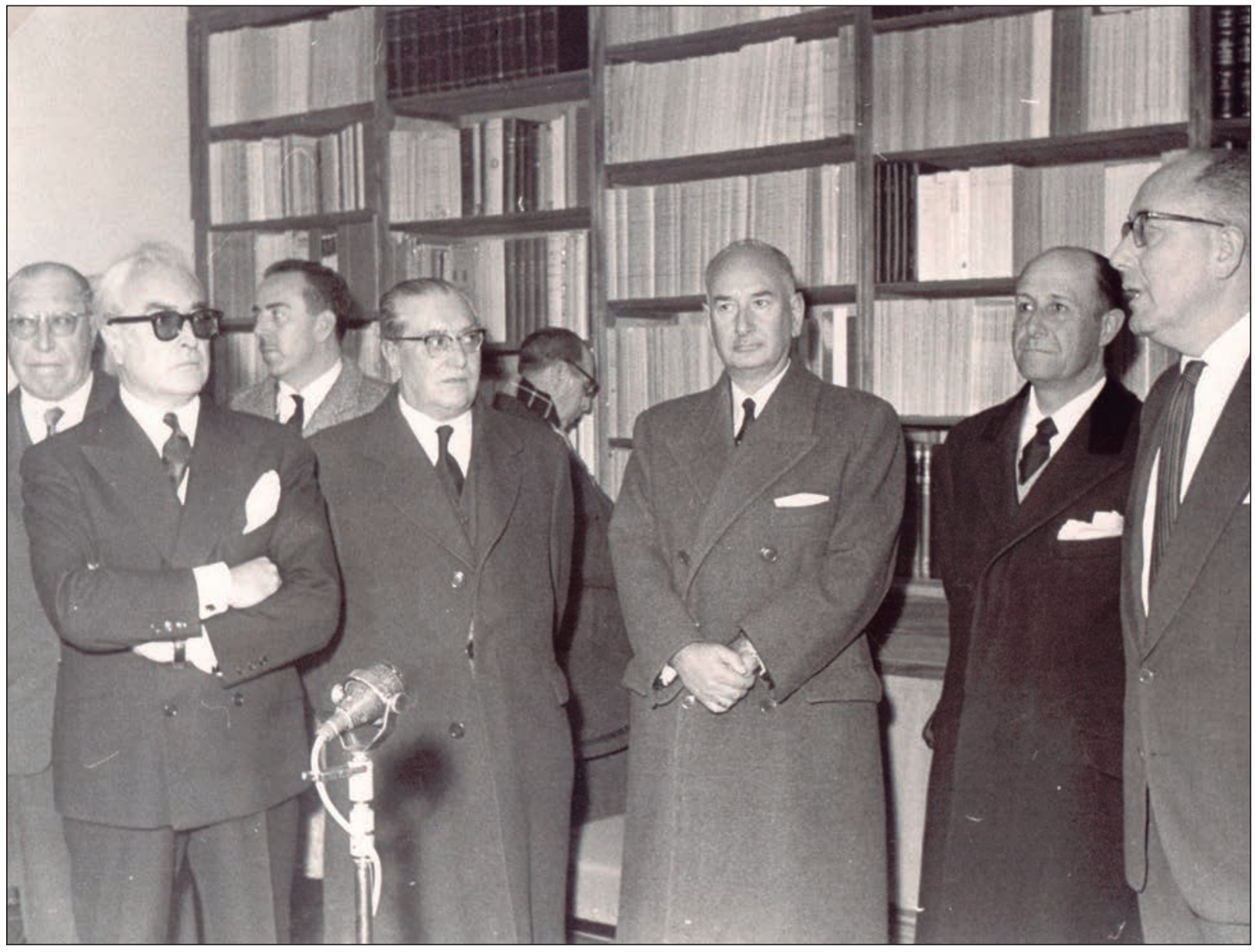

Fig. 1. Inauguración del Instituto Arqueológico Municipal el 11 de enero de 1961.

De izquierda a derecha Julio Martínez Santa-Olalla, el Alcalde de Madrid conde de Mayalde, el Ministro de la Vivienda don José Luis Arrese, don Manuel Maura y Salas y don José de C. Serra Rafols. 
depende hasta la creación en 1999 del Museo de San Isidro y el traslado de colecciones, biblioteca y archivos a su sede actual en la plaza de San Andrés.

Toda esta historia institucional tiene su reflejo en los fondos documentales del Museo de San Isidro en los que hay documentación de varias procedencias:

\section{Documentación del antiguo Museo Prehistórico Municipal}

Formada por las actas del Patronato del Museo y alguna documentación administrativa Los originales de esta documentación se encuentran en los fondos documentales del Museo de Historia de Madrid (Alaminos López, 1997).

La poca documentación científica que se encuentra en los fondos del Museo de San Isidro la forman planos y dibujos de las excavaciones que José Pérez de Barradas realizó antes de la Guerra Civil por cuenta del Ayuntamiento.

También se encuentra en este grupo de documentación la cartografía original y la elaborada por Pérez de Barradas para la exposición Información sobre la Ciudad celebrada en el Museo Municipal en 1929 de la que se publicó un magnífico volumen (Ayuntamiento de Madrid, 1929), (Priego Fernández del Campo, 2005). Esta exposición se montó con motivo de la elaboración del Plan General de Ordenación Urbana que por primera vez salía a información pública y en el que se trataban de manera integral todos los aspectos que afectaban a la planificación del crecimiento de la ciudad desde los geológicos y paleontológicos hasta los históricos, geográficos, sociológicos y económicos.

La documentación correspondiente a los aspectos geológicos, paleontológicos y prehistóricos la elaboró José Pérez de Barradas y se encuentra en este fondo documental.

A esta documentación hay que añadir planos, dibujos, informes, pruebas de imprenta de trabajos del Anuario de Prehistoria Madrileña y de la Revista de la Bibloteca, Archivo y Museo del Ayuntamiento de Madrid.

\section{Archivo de José Pérez de Barradas}

En diciembre de 2005 ingresó en el Museo de San Isidro un importante fondo documental comprado por el Ayuntamiento de Madrid a los hijos de don José Pérez de Barradas (González Alonso, 2008: 497-515). Junto con un interesante fondo documental formado por 9.100 documentos ingresó también una interesante biblioteca de más de 5.000 volúmenes de temas de Antropología y de América Prehispánica.

El fondo documental lo organizó mi compañero Alberto González Alonso en cuatro ámbitos: Ámbito personal, ámbito formativo, ámbito profesional y ámbito económico.
El mayor grupo de documentos está relacionado con la actividad de Pérez de Barradas en América y en su cátedra de Antropología de la Universidad Complutense (Figura 2).

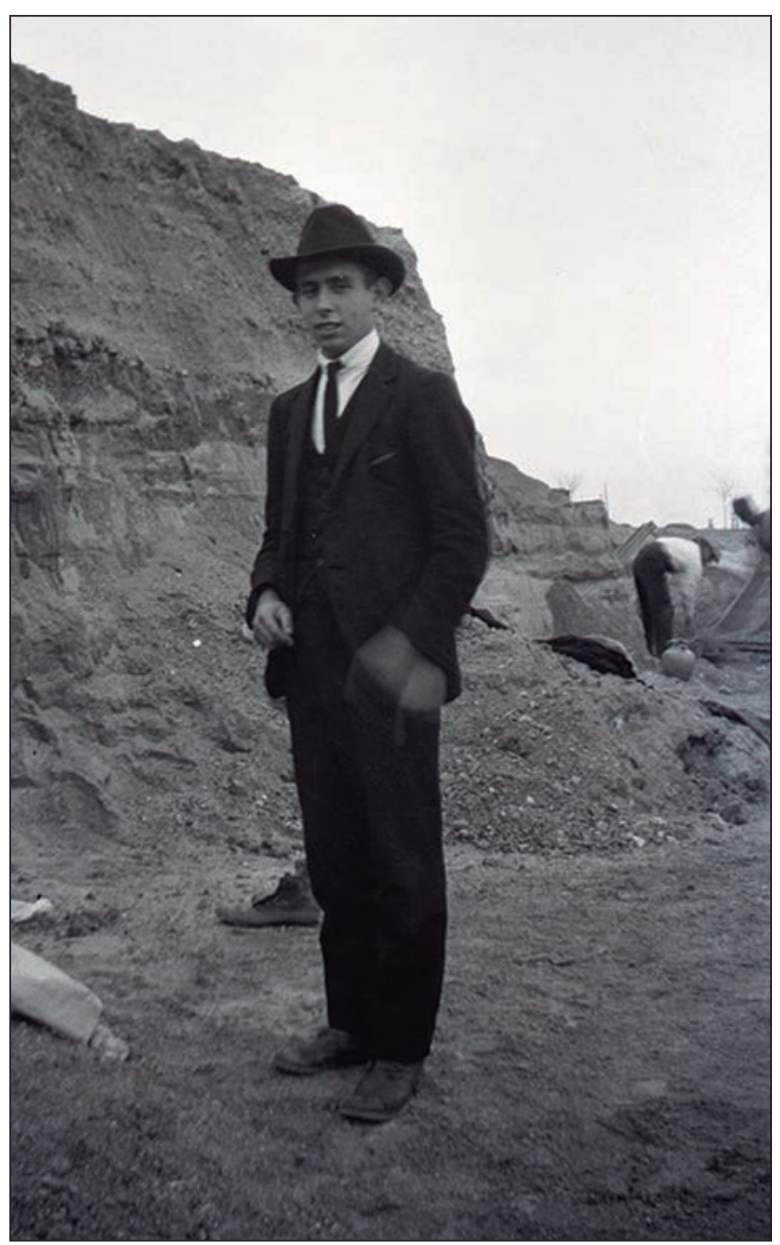

Fig. 2. José Pérez de Barradas en un arenero del Manzanares en 1918.

En lo referente a la actividad del Museo de San Isidro la documentación más interesante es la relativa a sus trabajos en la Arqueología madrileña desde 1917 hasta 1942. Este fondo ha permitido documentar, gracias a sus minuciosos diarios y apuntes, y a la buena cantidad de positivos y negativos fotográficos, yacimientos arqueológicos de los que apenas se tenían datos pues fueron arrasados por el crecimiento urbano de la ciudad. La identificación de buena parte de las imágenes ha sido muy compleja, ha habido que poner en relación las imágenes publicadas con las notas de los diarios y muchas veces se han identificado por los obreros que aparecen fotografiados en los yacimientos que se repiten en imágenes publicadas e inéditas o por alguna nota manuscrita en el reverso de las fotografías.

El periodo de la actividad profesional de Pérez de Barradas mejor representado, al menos en cuanto al número de documentos, es desde la Guerra Civil hasta los años 50. 


\section{EXPEDIENTES DE LA SECCIÓN Aroueológica del Museo Municipal}

Lo más importante de esta documentación son los inventarios que don Manuel Maura y Salas, Patrono del Museo Municipal, encargó a unos becarios en la posguerra, estos inventarios han permitido documentar detalladamente las aproximadamente 30.000 piezas arqueológicas procedentes de las actividades municipales desde 1927 a la Guerra Civil. Otra parte de la documentación la forman los expedientes de adquisiciones de piezas arqueológicas y de recuperación de patrimonio en el Valle del Manzanares en los primeros años de la posguerra, esta documentación está fotocopiada, los originales se encuentran en el Museo de Historia de Madrid.

\section{Documentación DeL InSTITUTO Aroueológico Municipal}

Éste es un fondo documental importante, recoge la actividad administrativa y científica de toda la vida del Instituto lo forman varios miles de documentos, planos, dibujos, fotografías, películas del antiguo NODO, cintas magnetofónicas con conferencias grabadas, análisis de todo tipo, informes de restauración, etc. Con esta documentación se puede seguir toda la actividad municipal y científica de este organismo desde los años 60 hasta 1999.

Además de la actividad administrativa y científica del Instituto reflejada en los documentos, hay varios millares de recortes de prensa de artículos y noticias relacionadas con la arqueología entre los que destaca un importante fondo dedicado a Madrid.

\section{Archivo personal de Julio Martínez Santa-Olalla}

Es el fondo más importante de todos, estaba depositado en la sede del antiguo Instituto Arqueológico Municipal donde permaneció mezclado con la documentación administrativa municipal e ignorado hasta que se produjo el traslado de las colecciones, biblioteca y archivo a la nueva sede del Museo de San Isidro en la Plaza de San Andrés de Madrid. Dada la importancia de este fondo lo trataremos con más detalle más adelante.

\section{Donación de doña Raquel Castelo RUANO}

En abril de 2004 doña Raquel Castelo Ruano, profesora de la Universidad Autónoma de Madrid, hizo entrega de un fondo documental procedente del Dr. Óscar Soriano. Este importante fondo documental complementa el archivo personal de Julio Martínez Santa-Olalla y procede de una cuñada suya, es posible que fuera una parte del mismo archivo personal que por alguna circunstancia quedó en su casa.

La donación la formaban cuatro carpetas con más de 300 documentos. La documentación más importante de este fondo la forman una serie de trabajos y conferencias inéditos rescatados por R. Castelo, Ruano L. M. Cardito Rollán, Panizo Arias y Rodríguez Casanova en una publicación editada a sus expensas (VV. AA., 1995). Acompañan a estos trabajos una reducida correspondencia, dibujos, algunos de los cuales también se encuentran en el archivo personal, fichas de Arqueología norteafricana que complementan gráficamente la abundante documentación de su archivo personal. Fotografías de diversos yacimientos y de piezas, destacan las fotografías de la Expedición Paletnológica al Sahara Español con sus correspondientes fichas y 110 fotografías de carácter etnográfico y arqueológico (Figura 3)

Julio Martínez Santa-Olalla recogía sistemáticamente todos los recortes de prensa, invitaciones a conferencias y actos y referencias a sus actividades y a sus centros de interés (Arqueología, Paletnología, Arte, etc.), por eso en este fondo se encuentran estos recortes, pero también los hay en el fondo del Instituto Arqueológico Municipal, en su archivo personal, en el legado de Bernardo Sáez Martín.

\section{Legado Sáez Martín}

Bernardo Sáez Martín fue un estrecho colaborador de Julio Martínez Santa-Olalla desde los primeros años cuarenta hasta 1971 , le acompañaba en todos sus viajes y participaba en todas sus excavaciones y actividades, su relación era tan estrecha que a la muerte de Santa-Olalla presentó su dimisión en el puesto de Jefe de trabajos de campo y laboratorios que ocupaba en el Instituto Arqueológico Municipal. Era coleccionista lo mismo que su mentor y posiblemente esa faceta fue la que inició y fomentó su relación.

A su muerte legó a los museos municipales de Madrid todas sus colecciones y mobiliario dejando como usufructuario a don Óscar Segovia quien tuvo la generosidad de renunciar a buena parte del usufructo permitiendo que las colecciones y buena parte de la biblioteca pasaran al Museo de San Isidro junto con alguna documentación. A la muerte de Óscar Segovia, el mobiliario y el resto de la biblioteca ingresaron en el museo (Museo de San Isidro, 2006).

Los fondos documentales son muy poco importantes los forman algunos documentos de las actividades que realizó Bernardo Sáez con Julio Martínez Santa-Olalla y fotografías, muchas de ellas presentes en el archivo personal de Santa-Olalla y en el archivo del propio Instituto Arqueológico Municipal, de 


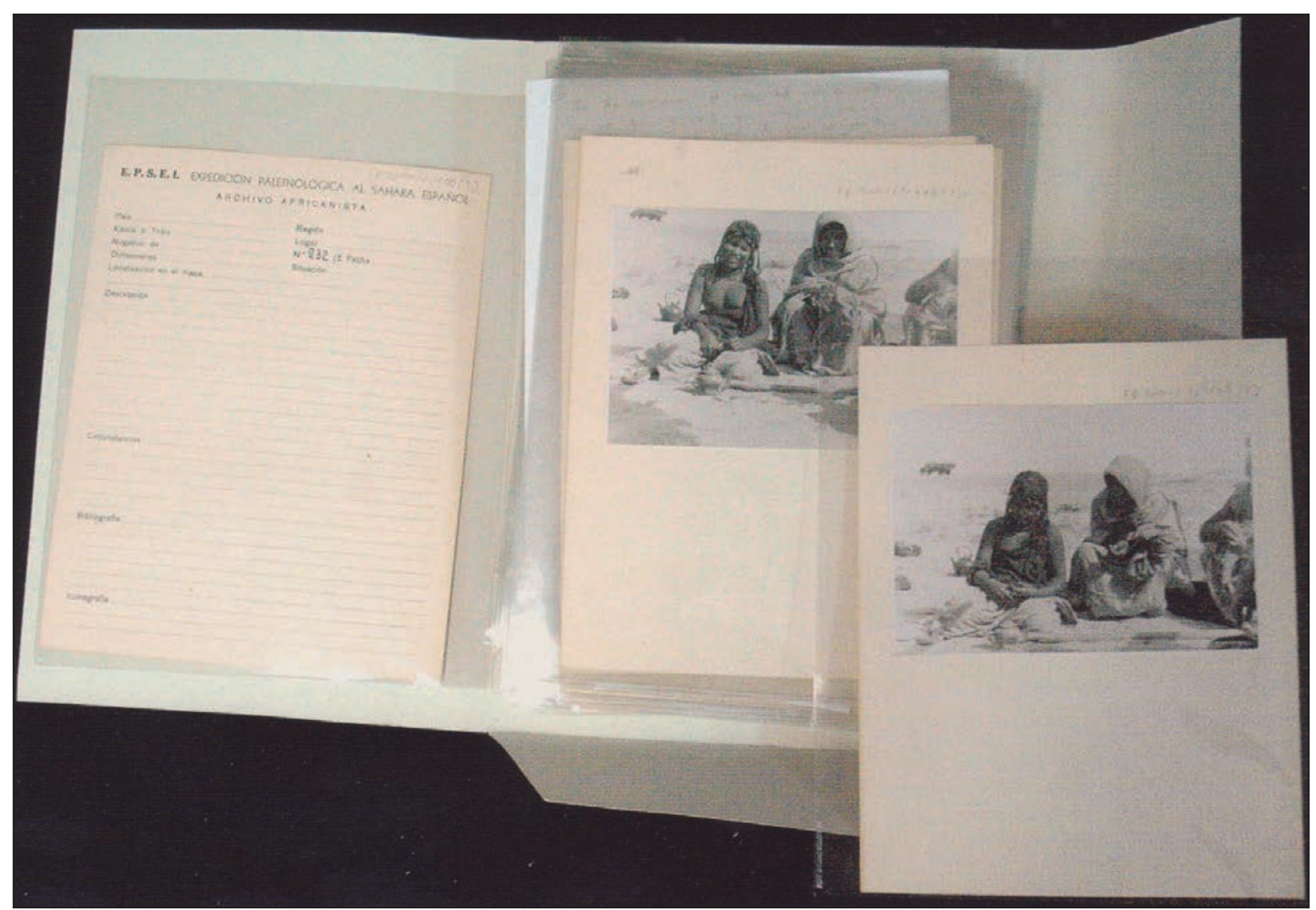

Fig. 3. Donación de Raquel Castelo. Encapsulado actual de documentos.

las excavaciones del Ayuntamiento de Madrid en Orcasitas, mastodonte de Mirasierra, areneros del Manzanares, Canarias y Carteia; además acompaña una buena serie de fotografías de la Expedición Paletnológica al Sahara Español de 1943, de la Expedición a Guinea y de viajes por España y Portugal.

\section{Archivo personal de Julio Martínez Santa Olalla}

Constituye este fondo un importantísimo archivo con más de 80.000 documentos de todo tipo, desde documentos de carácter personal y casi íntimo hasta documentos de carácter institucional de los diferentes cargos que ocupó a lo largo de su vida. Cronológicamente cubre entre 1922 y los últimos años sesenta. Este archivo es fundamental para el conocimiento de la historia institucional de la arqueología española sobre todo en la época del primer franquismo.

El fondo documental se encontraba en el Instituto Arqueológico Municipal sin diferenciación alguna con la documentación administrativa de la institución. Se trataba de cerca de 100 archivadores de oficina colocados en estanterías, algunos tenían indicación aproximada del contenido como C.I.A.O. (Conferencia Internacional de Africanistas
Occidentales), Seminario (se refería al Seminario de Historia Primitiva), Congresos, Santander (Escuelas de verano con la realización de sendas excavaciones arqueológicas en la Cueva del Pendo en 1953 y 1957), etc. También se encontraban carpetas con diarios de excavaciones de Castiltierra, Villel de Mesa, Tabernas, Carteia, etc.

El estado de conservación del fondo documental era muy precario, en primer lugar por el propio sistema de archivo, archivadores de cartón con anillas muchas de ellas oxidadas (Figura 4). Los documentos no tenían más protección que los propios archivadores que como sabemos están abiertos por tres de sus lados, con lo que estuvieron varias décadas sometidos al polvo ambiental, el soporte de buena parte de los documentos, aproximadamente el 50\% es de papel cebolla, las hojas de separación para indexar los documentos son tan ácidas que transmiten la acidez a los documentos, esta acidez es extrema en el caso de los telegramas.

Antes de proceder al inventariado y catalogación del fondo documental procedimos a la limpieza física de los documentos y a su traslado a carpetas de cartulina neutra, en el caso de los documentos con mucha acidez como son los telegramas, procedimos a encapsularlos en bolsas de acetato neutro, este 


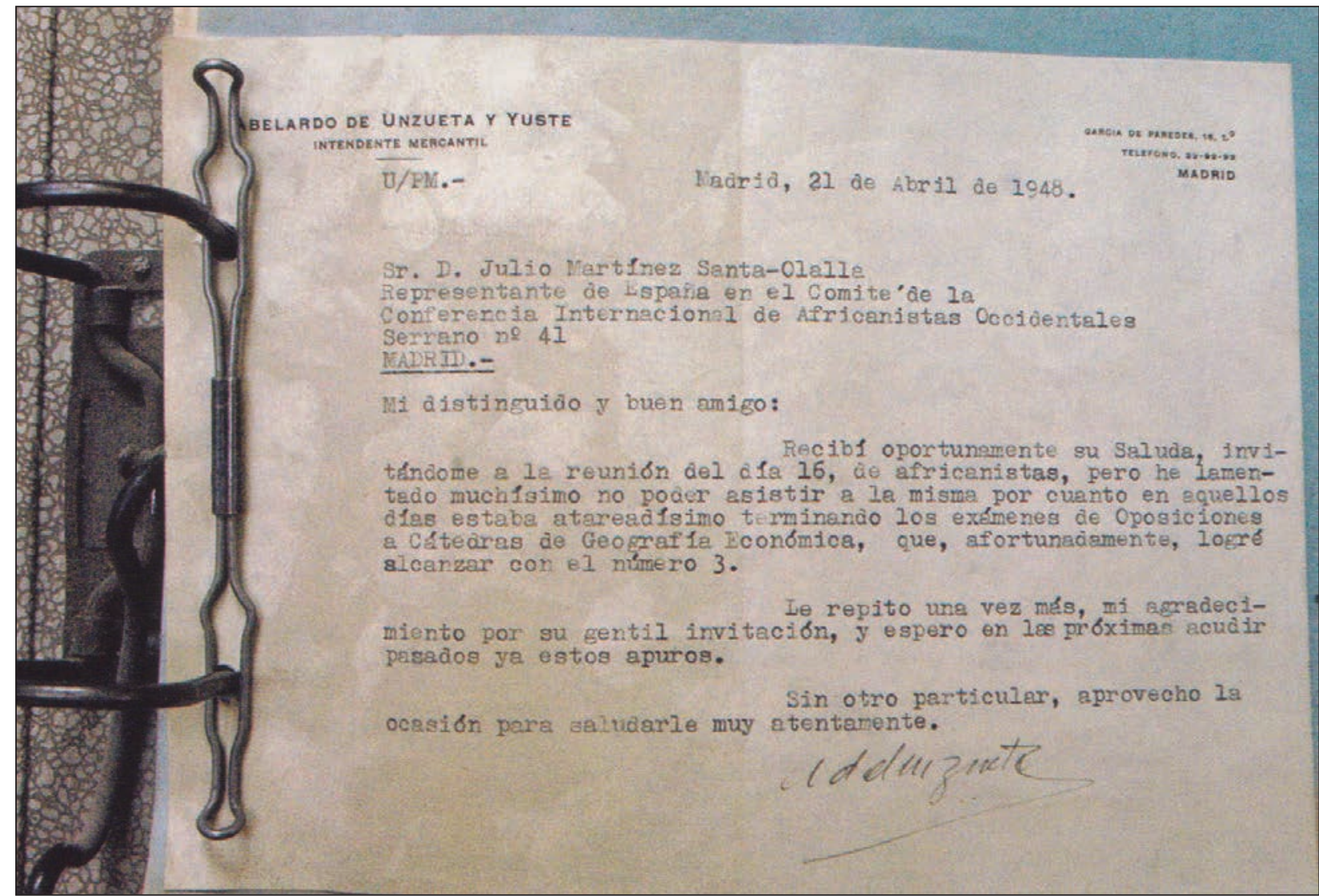

Fig. 4. Mecanismo de sujeción de documentos del archivo personal de Santa-Olalla con evidencias de oxidación.

mismo procedimiento lo seguimos con los positivos y negativos de fotografías y con los dibujos. Las carpetas de cartulina neutra con la documentación numerada y controlada fueron depositadas a su vez en cajas de cartón neutro con la documentación en sentido horizontal para evitar deformaciones del papel (Figura 5)

En la actualidad se está procediendo al inventariado y catalogación de todo el fondo documental, se están escaneando los documentos e incorporando al sistema integral de gestión de museos que el Ministerio de Cultura ha puesto a disposición de numerosos museos españoles (DOMUS).

\section{CONTENIdO DEL FONDO DOCUMENTAL}

El archivo personal de Julio Martínez Santa-Olalla contiene cartas personales dirigidas o recibidas de infinidad de personajes de la vida política, académica y científica tanto nacional como internacional; originales de trabajos científicos suyos y de otros colegas, buena parte de ellos publicados y otros inéditos; planos, dibujos y fotografías; diarios de excavaciones, informes científicos de análisis, correspondencia de las diversas cátedras que ocupó a lo largo de su vida, notas de preparación de las clases, textos de conferencias, trabajos de alumnos, etc.
El archivo ha llegado a nosotros con un orden que se nos escapa, en algunos casos los archivadores estaban agrupados por temas, en otros por fechas, en otros por orden alfabético. Parece como si diferentes personas en momentos diferentes hubieran intentado organizar el archivo. En alguno de los traslados que experimentó el archivo se debieron mezclar documentos de diferente procedencia, pues en un mismo archivador aparecen documentos de fechas muy diferentes que no tienen relación temática alguna. La documentación mejor organizada es la anterior a la Guerra Civil.

Los temas principales del fondo documental son los mismos temas que trabajó Santa-Olalla, así hay abundante documentación relativa al mundo visigodo consistente en correspondencia con sus colegas de toda Europa, borradores de artículos, diarios de excavaciones, dibujos de materiales, planos, fotografías de los cementerios visigodos de Herrera de Pisuerga, Madrid capital, Castiltierra, Villel de Mesa, Duratón, etc., notas preparatorias para recensiones de trabajos extranjeros sobre el mundo visigodo, notas preparatorias para las clases, etc

África fue otra de sus obsesiones reflejada en numerosa documentación de todo tipo de congresos como el mencionado de CIAO (Congreso Internacional de Africanistas Occidentales), el congreso de Dakar, correspondencia con el IFAN (Institut 


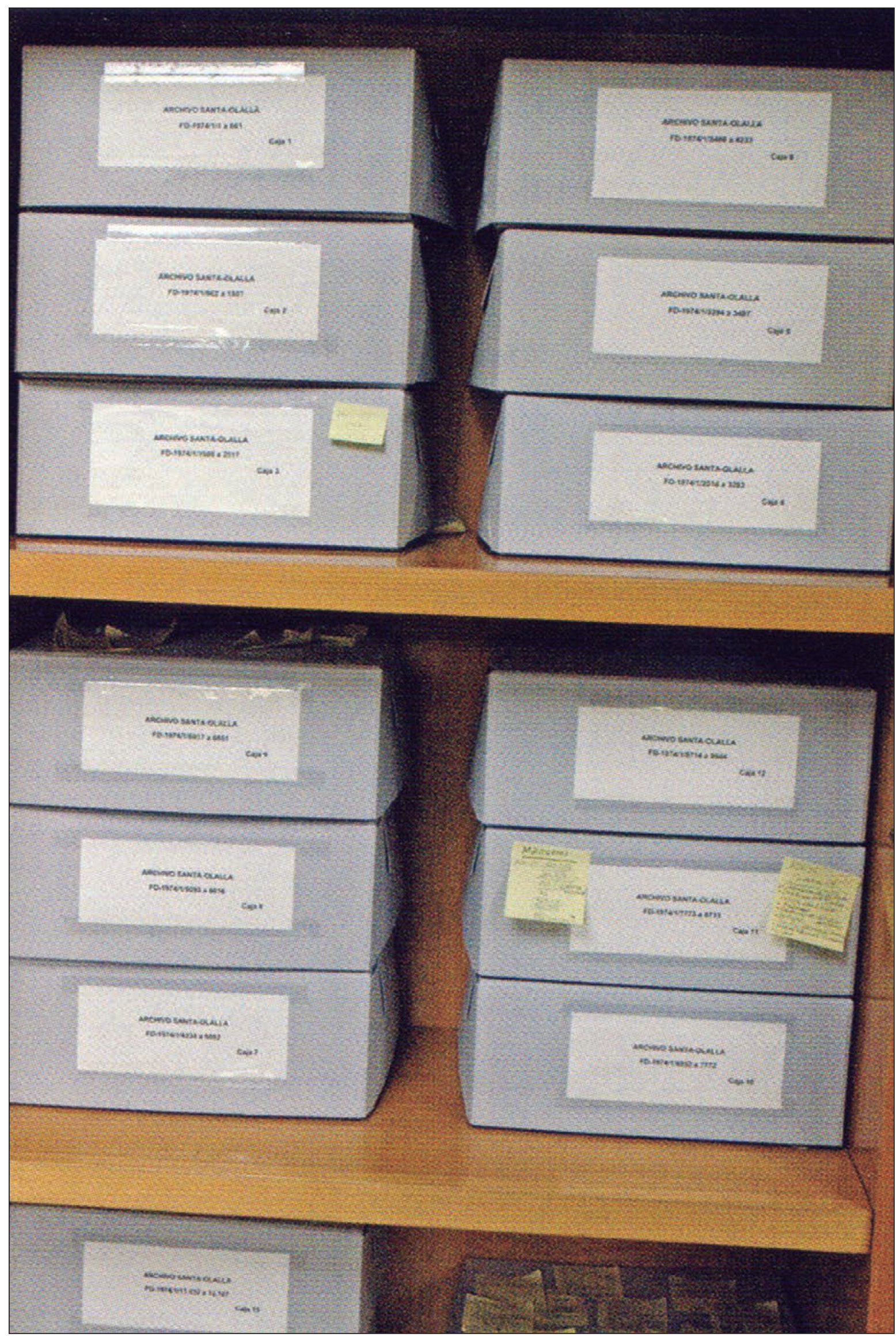

Fig. 5. Estado actual del archivo con los documentos depositados en horizontal en carpetillas de cartulina neutra y éstas en cajas de cartón neutro. 
Français d'Afrique Noire, tras la independencia Institut Fondamental d'Afrique Noire). Mantuvo una activa correspondencia con Henry Lothe o con el Museo del Bardo de Túnez. Abundante documentación referente a la Alta Comisaría de España en Marruecos y un apartado muy importante y abundante de documentación de las Islas Canarias entre la que destaca la correspondencia mantenida con Diego Cuscoy, Sebastián Jiménez Sánchez, Dominique Wöfel, Ilse Schwidetzky, Elías Serra Rafols.

Otro apartado importante lo constituye la documentación sobre el Seminario de Historia Primitiva del Hombre de la Universidad Central, si bien una buena parte de esta documentación es bastante aburrida y da muy poca información, se trata del control de intercambios de publicaciones.

En la actualidad se está procediendo a la digitalización de todos los documentos y hasta el momento han generado las siguientes entradas:

Las entradas en las que no figura entre paréntesis el número de documentos es porque éstos aún no han sido escaneados. El criterio seguido para la digitalización de los documentos lo han marcado las peticiones de los investigadores.

- Ahnenerbe (53 archivos):

- Himmler, Heinrich

- Instituto de Estudios Paletnológicos y Etnográficos (intento de creación de una Ahnenerbe española)

- Sievers, Wolfram

- Winzer, Paul

- Wüst, Walther

- Alcalde del Río, Hermilio (2 documentos)

- Alföldi, Andreas (3 documentos)

- Almagro Basch, Martín (27 documentos)

- Alonso del Real, Carlos (6 documentos, pero hay muchos más sin escanear)

- Althin, Carl Axel (2 documentos)

- Álvarez Ossorio, F.

- Arrese, J.L. (incontables documentos)

- Atapuerca (85 archivos)

- Avigad, N. (1 archivo)

- Ballester Tormo, Isidro

- Ballesteros Beretta, Antonio

- Banner Janos

- Bardavíu Ponz

- Barras y Aragón, Francisco de las (15 archivos)

- Bastarreche, Almirante (incontables)

- Bégouen, Conde de

- Behn, Friedrich

- Behrens, G.
- Benain, David

- Bernice P. Bishop Museum (3 documentos)

- Bersu, Anne Maria

- Bersu, Gerhard

- Bertoldi, Vittorio

- Böe, Johs

- Boletín de Información Cultural

- Bonsor, Jorge (2 documentos)

- Bosch i Gimpera, Pere (210 archivos)

- Boule, Marcellin

- Breuil, W.Henri (7 documentos)

- Brogger, A.

- Burgos (4 archivos)

- Burkitt, Miles

- Cabeza, Salvador (16 archivos)

- Calza, Guido

- Camón Aznar, José

- Camps Cazorla, Emilio

- Canarias

- Diego Guscoy (16 escaneados, pero hay muchos más)

- Jiménez Sánchez (37 imágenes e incontables documentos)

- Schwidetzky, Ilse (10 documentos)

- Serra Rafols, José de C. (8 archivos)

- Val Caturla (30 archivos)

- Wölfel (4 archivos)

- Carballo García, Jesús

- Carpenter, Rhys

- Carteia (109 archivos)

- Castillo, Ángel del

- Castillo Yurrita, Alberto del (2 archivos)

- Charles, P.

- Castiltierra (570 archivos)

- Caturla, $\mathrm{M}^{\mathrm{a}}$ Luisa

- Cheesmann Rodríguez, Roberto

- Childe, V. Gordon (134 archivos)

- Chocomeli, José

- Chookshank, J. K.

- Clark, John Desmond (22 archivos)

- Colominas i Roca, Joseph

- Comillas, marqués de

- Conde de la Vega del Sella

- Contreras.y López de Ayala, Juan de

- Coutil, Leon

- Crawford, Osbert Guy Stanhope

- Cuadrado, Emeterio (17 archivos, pero hay muchos más) 
- Cullalvera, caverna de la (3 fotografías)

- Curtius

- Daniel, A. Glen (4 archivos)

- Debod, templo de

- Delbrueck, Richard

- Deutsche Vorgeschichte (13 archivos)

- Domecq, Álvaro

- Droop, J. P.

- Embajada de Francia

- Erdélyi, G.

- Facultad, Madrid (11 archivos)

- Facultad, Zaragoza

- Facultad, Valencia

- Fernández Chicarro, C. (10 archivos, pero hay muchos más)

- Fernández Menéndez, José Luis

- Fettich Nándor

- Flaquer y Fábregues, Juan (6 archivos)

- Fletcher Valls, Domingo (58 archivos)

- Fraga Iribarne, Manuel

- Frobenius, Leo

- Fuidio Rodríguez, Fidel

- Gaerte, Wilhelm

- Gaiteiro, M. (2 documentos)

- García y Bellido, A.

- Gaya Nuño, Juan Antonio

- Gener Cuadrado, Eduardo

- Glazema, Peter

- González, Fr. Sarurio González Echegaray, Joaquín

- González Salas, Saturio (24 archivos)

- Grupo Universitario Fascista

- Guinea

- Gusendos, Teófilo de

- Haevernich, Thea Elisabeth

- Hamal-Nandrin, Joseph

- Hebrew University, Jerusalem

- Hekler, Antal

- Hemp, Wilfrid J

- Hoffmann, E.

- Horváth, T

- Hougen, Bjorn

- Huidobro Serna, Luciano (22 archivos)

- Ibero, José $\mathrm{M}^{\mathrm{a}}$ (28 archivos)

- Informes y proyectos (99 archivos)

- Instituto Arqueológico Alemán (15 archivos)

- Instituto de Estudios Ibéricos y Etnología Valenciana (1 documento)
- Irán (1 documento)

- Iraq

- Jacobsthal, Paul

- Jalhay, Eugenio (141 archivos)

- Jiménez Cuenca, Manuel

- Jordá, Cerdá, F.

- Junker, Hermann

- Juyo, cueva del (5 fotografías)

- Kendrick, Sir Thomas Downing

- Koehler, Henry

- Konen, Heinrich Mathias

- Kossina, Gustav

- Kroft, Paul van der

- Kühn, Herbert

- Kutrzeba, Stanisław Marian

- Lafuente Ferrari

- Lafuente Vanrell, Lorenzo

- Langsdorff, A

- Larín, Blas

- Lasso de la Vega, Javier

- Laver

- Lebzelter, Viktor

- Lafuente Ferrari

- Lafuente Vanrell, Lorenzo

- Langsdorff, A

- Larín, Blas (2 documentos)

- Lasso de la Vega, Javier

- Laver

- Laviosa Zambotti, Pía (10 archivos)

- Leakey, L.S.B. (1 documento)

- Lebzelter, Viktor

- Lequerica, José Félix de

- Linckenheld, Emile

- Lodge, John David

- López Cuevillas, Florentino (16 documentos)

- López Ibor, Juan José

- Loriana, Marqués de (2 archivos)

- Lowe, C. van Hist (1 documento)

- Luengo Martínez, José $\mathrm{M}^{\mathrm{a}}$

- Madrid (296 archivos)

- Aguinaga, Enrique de (1 documento)

- Aguirre, Emiliano (2 archivos)

- Angosto G. Vaso, José Ángel (2 archivos)

- Arrese, J.L. (19 archivos)

- Bandi, G. (1 documento)

- Calvo, Ismael (1 documento)

- Casares, Francisco (9 archivos) 
- Cerro Corrochano, Tomás (3 archivos)

- Cierva, Piedad de (2 documentos)

- Comisaría General para la Ordenación Urbana (1 documento)

- Congreso 1954 (221 archivos)

- Cornwall (I. W. (1 documento)

- Conde de Mayalde (7 archivos)

- Conde de Montarco (2 archivos

- Gistau, Tomás (2 documentos)

- Hoyos Sainz, Luis de (13 archivos)

- Institución Cultural Jiménez de Cisneros (5 archivos)

- Instituto Arqueológico Municipal (2 archivos)

- Juretschke, Hans (2 documentos)

- Marqués de la Valdavia (17 archivos)

- Mateo Muñoz, Juan (3 archivos)

- Muguruza Otaño, Pedro (2 archivos)

- Ossorio Otaño, Juan Lios (1 documento)

- Oswald, Capitán (1 documento)

- Pietch, E. (1 documento)

- Plaza, Marcos (10 documentos)

- Vaufrey, R. (2 archivos)

- Mahón (4 archivos)

- Mahr, Adolf (2 archivos)

- Marqués de Comillas (1 documento)

- Marqués de Lozoya (2 documentos)

- Marruecos y Colonias (259 archivos)

- Alemani, Bernardo (2 documentos)

- Alta Comisaría de España en Marruecos (3 documentos)

- Arques, Enrique (1 documento)

- Bermejo, José (1 documento)

- Carbajo, Tte. Cor. (1 documento)

- Carcopino, J. (1 documento)

- Castiella, Fernando M M $^{\mathrm{a}}$ (4 archivos)

- Castillo Campos, Cristóbal del (5 archivos)

- Cebral, M.R. (4 documentos)

- Dávila, Fidel (4 archivos)

- Díaz de Villegas, José (26 archivos)

- Domenech, Ángel (8 archivos)

- Erola, José (1 documento)

- Español y Coll, Francisco (1 documento)

- Fontán Juan (4 archivos)

- Galera, Alfredo (1 documento)

- García Bengoechea (1 documento)

- García Figueras, Tomás (32 archivos)

- Gil Benumeya, Rodolfo (4 archivos)
- Gómez Acebo, José R. (6 archivos)

- Guinea, Emilio (2 documentos)

- Gutiérrez Sesma, Juan Antonio (4 archivos)

- Jatib, Sid Mohamed el (4 archivos)

- Koehler, Henry (3 archivos)

- Lamarque, Francisco (1 documento)

- Lavedán Navarro, Manuel (1 documento)

- Linares Maza, Antonio (1 documento)

- Lombardero, Manuel (2 documentos)

- Magara, Sauar (1 documento)

- Martín Alonso, Nicolás (10 archivos)

- Martín, Joaquín (2 documentos)

- Mateu, Joaquín (4 documentos)

- Miguel, Joaquín (8 archivos)

- Ministerio de AA. EE. (4 archivos)

- Monod, Theodor (8 archivos)

- Montalbán y de Mazas, C. (1 documento)

- Morales Agacino, E. (4 documentos)

- Núñez, Jorge (1 documento)

- Orzalesi, Egidio (2 documentos)

- Pérez Barrueco, Rufino (1 documento)

- Propper de Castejón, Eduardo (2 documentos)

- Rodríguez de Valcárcel, Carlos Mª (1 documento)

- Rodríguez, Juan (3 documentos)

- Ruhlmannn, Armand (4 documentos)

- Sánchez Plasencia (1 documento)

- Santos Gallego (14 archivos)

- Torres, Abdeljalak (2 documentos)

- Varela, Enrique (6 documentos)

- Villalobos y Belsel, Domiciano (3 documentos)

- Martínez Anido, Severiano

- Martín Artajo, Alberto (1 documento)

- Maura y Salas, Manuel (56 archivos)

- Mélida Alinari (2 documentos)

- Menéndez Pidal, Ramón

- Ministerio de Instrucción Pública (11 archivos)

- Monod, Theodor (1 documento)

- Obermaier, H. (80 archivos)

- Ors, Eugenio d'

- Osten, Hans, Henning von der (51 archivos)

- Oswald, Felix

- Ourvantzoff, Miguel (10 archivos)

- Paulsen, Rudolf (1 documento)

- Pendo, Cueva del (83 archivos)

- Peralada, Conde de

- Pérez Bustamante, José (17 archivos)

- Pérez Bustamante de la Vega, Ciriaco 
- Pérez de Barradas, José (46 archivos)

- Pericot García, Lluis (206 archivos)

- Perkins, John Ward

- Pinar, Cueva del (2 fotografías)

- Pinto, Ruy Correa da Serpa

- Porcar, J. B. (1 documento)

- Porcuna

- Barranco Cobo, Antonio (1 documento)

- Portugal

- Athayde, Alfredo (1 archivo)

- Cardozo, Mario (4 archivos)

- Companhia de Diamantes de Angola (1 archivo)

- Fragoso de Lima (1 documento)

- Leisner, Georg

- Leisner, Vera

- Mendes Correa, A. A.

- Teixeira, Carlos (1 documento)

- Viana, Abel (1 documento)

- Zbyszewski, Georges (1 documento)

- Posac Mon, Carlos (142 archivos)

- Post, Chandler Rafton (3 documentos)

- Poulsen, Frederik (3 documentos)

- Presedo, Francisco (19 archivos)

- Proske

- Radford, Ralegh

- Radio Nacional de España

- Reinerth, Hans

- Reinhart, W. (10 archivos)

- Rodenwaldt, Gerhart

- Ruiz Argilés, Vicente (3 documentos)

- Sánchez y Sánchez, Domingo

- Sánchez Sarto, Manuel

- Santander (19 archivos)

- Schlunk (13 archivos)

- Schober, Arnold

- Schuchhardt, Carl

- Schulten, Adolf (114 archivos)

- Schulz, Agnes

- Schwidetzsky, Ilse (46 archivos)

- Seminario de Historia Primitiva

- Sociedad Española de Antropología, Etnografía y Prehistoria

- Serra Rafols, Elías de C. (13 archivos)

- Serra Rafols, J. De C. (53 archivos)

- Siret, L. (3 documentos)

- Söllner

- Sprockhoff, Ernst
- Stieren, August

- Stocky, Albin

- Tallgren, Aarne Michaël

- Taracena Aguirre, Blas (3 documentos)

- Taramelli, Antonio

- Thiry, Gertrud

- Tompa, Ferenç von

- Tormo y Monzó, Elías

- Totana (4 documentos)

- Tuya Solar, Ángel de

- UNESCO (3 archivos)

- Unverzagt, Wilhelm

- Val Caturla, Eduardo del (6 archivos)

- Valladolid

- Vaufrey (23 archivos)

- Victory Manella, Juan

- Vilaseca, Salvador (51 archivos)

- Villel de Mesa (18 archivos)

- Wallraf Richartz Museum

- Wegner, Max

- Weiser, G. (1 documento)

- Werner, Joachim

- Wernert, Paul (3 archivos)

- Wiegand, Theodor

- Zammit, Temistocles

- Zammit, C. G.

- Zeiss, Hans

Esta documentación hasta el momento ha servido en buena parte de base para artículos y libros como los publicados por el profesor de la Universidad de Barcelona don Francisco Gracia (2009 y 2011), Alfredo Mederos, (2011) o nosotros (2002 y 2006). Cuando concluya el escaneado de los documentos y su procesamiento archivístico, los investigadores encontrarán una herramienta eficaz e imprescindible para estudiar la historiografía de la arqueología española en buena parte del siglo XX.

\section{Conclusiones}

De los fondos documentales del Museo de San Isidro de Madrid el más numeroso y el que mayor información nos proporciona es el de Julio Martínez Santa-Olalla que fue un personaje clave en la institucionalización de la arqueología española tras la Guerra Civil. El análisis de la documentación de su archivo personal, su contraste con el archivo personal de Pérez de Barradas, con el de la Fundación Bosch i Gimpera (Gracia, F., Fullola, M. y Vilanova, F., 2002), archivos universitarios, Archivo General de la Administración, etc, nos darán una visión bastante aproximada de cómo 
se construyó el entramado institucional de la arqueología y de cómo eran las relaciones entre los actores de ese entramado con sus grandezas y miserias.

\section{Bibliografía}

Alaminos López, E. (1997): Actas del Patronato del Museo Municipal (1927-1947). Madrid. Museo Municipal.

Ayuntamiento de Madrid (1929): Información sobre la Ciudad. Madrid

Museo de San Isidro (2006). El legado Sáez Martín a los Museos Municipales de Madrid. Madrid.

González Alonso, A. (2008): El hilo de Ariadna: Guía para la utilización del archivo personal de José Pérez de Barradas. Arqueología, América, Antropología. José Pérez de Barradas. 1897-1981. Madrid: 497-515.

Gracia Alonso, F. (2009): La Arqueología durante el primer franquismo (1939-1956). Barcelona, Ed. Bellaterra

Gracia Alonso, F. (2011): Pere Bosch Gimpera. Universidad, política, exilio. Marcial Pons. Madrid.

Gracia, F., Fullola, M. y Vilanova, F. (2002): 58 anys $t$ 7 dies. Correspondencia de Pere Bosch Gimpera a Lluis Pericot (1919-1974). Barcelona, Universidad y Fundación Bosch i Gimpera.

Mederos Martín, A. (2004): "Julio Martínez SantaOlalla y la interpretación aria de la Prehistoria de
España (1939-1945)". Boletín del Seminario de Estudios de Arte y Arqueología, 69-70: 13-55.

Mederos Martín, A. y Escribano Cobo, G. (2011): Julio Martínez Santa-Olalla, Luis Diego Cuscoy y la Comisaría Provincial de Excavaciones Arqueológicas de Canarias Occidentales (19391955) Santa Cruz de Tenerife: Museo Arqueológico de Tenerife

Museos de Madrid. Adquisiciones y proyectos (2007): Museo de los Orígenes. Adquisiciones 2003-2006. Madrid, Ayuntamiento de Madrid.

Priego Fernández del Campo, C. (ed.) (2005): Memoria. Información sobre la Ciudad. Año 1929. Ciclo de conferencias. Madrid, 4-6 de octubre de 2005.

Quero Castro, S. (1996): "Cuarenta años del Instituto Arqueológico Municipal”. Estudios de Prehistoria y Arqueología Madrileñas 10: 193-200.

Quero Castro, S. (2002): La Investigación del Paleolítico en Madrid durante el franquismo (1936-1971). Bifaces y elefantes. Zona Arqueológica 1: 168-194.

Quero Castro, S. (2006): La investigación sobre el mundo visigodo en Madrid desde la Guerra Civil a la transición democrática. Zona Arqueológica, 8 (1): 2-12.

VV.AA. (1995): Julio Martínez Santa-Olalla. Crónicas de la cultura arqueológica española. Madrid. 